\title{
Papers
}

\section{Driver sleepiness and risk of serious injury to car occupants: population based case control study}

\author{
Jennie Connor, Robyn Norton, Shanthi Ameratunga, Elizabeth Robinson, Ian Civil, Roger Dunn, \\ John Bailey, Rod Jackson
}

\begin{abstract}
Objectives To estimate the contribution of driver sleepiness to the causes of car crash injuries. Design Population based case control study. Setting Auckland region of New Zealand, April 1998 to July 1999.

Participants 571 car drivers involved in crashes where at least one occupant was admitted to hospital or killed ("injury crash"); 588 car drivers recruited while driving on public roads (controls), representative of all time spent driving in the study region during the study period.

Main outcome measures Relative risk for injury crash associated with driver characteristics related to sleep, and the population attributable risk for driver sleepiness.

Results There was a strong association between measures of acute sleepiness and the risk of an injury crash. After adjustment for major confounders significantly increased risk was associated with drivers who identified themselves as sleepy (Stanford sleepiness score 4-7 $v 1$ 1-3; odds ratio 8.2, 95\% confidence interval 3.4 to 19.7 ); with drivers who reported five hours or less of sleep in the previous 24 hours compared with more than five hours (2.7, 1.4 to 5.4); and with driving between 2 am and 5 am compared with other times of day (5.6, 1.4 to 22.7). No increase in risk was associated with measures of chronic sleepiness. The population attributable risk for driving with one or more of the acute sleepiness risk factors was $19 \%$ (15\% to $25 \%$ ).

Conclusions Acute sleepiness in car drivers significantly increases the risk of a crash in which a car occupant is injured or killed. Reductions in road traffic injuries may be achieved if fewer people drive when they are sleepy or have been deprived of sleep or drive between 2 am and $5 \mathrm{am}$.
\end{abstract}

\section{Introduction}

Sleepiness in drivers is widely believed to be an important cause of road traffic injuries and so quantifying its contribution to crashes is important for the development and prioritisation of interventions to prevent these injuries. Published estimates of the proportion of crashes attributable to sleepiness vary more than tenfold, from $1-3 \%$ for the United States ${ }^{1}$ to $10 \%$ in
France $^{2}$ and 33\% in Australia. ${ }^{3}$ This variation reflects the quality of the data available as these figures are derived from descriptive information about crashes. Controlled studies that have estimated the prevalence of driver sleepiness and the associated risks have been limited by methodological problems, including the study of non-representative populations, focus on medical causes of sleepiness rather than sleepiness per se, and investigation of the incidence of crashes rather than injuries. ${ }^{4-6}$

Measures of acute and chronic sleepiness, sleep restriction, sleep disorders, and work patterns that interfere with normal sleep have been associated with decreased performance in psychomotor tests and driving simulators ${ }^{7-11}$ and with increased rates of crashes in selected populations. ${ }^{5}$ We examined the association of these sleep related characteristics with the risk of crashes in which a car occupant is injured or killed in a regional population.

\section{Methods}

We carried out a population based case control study in the Auckland region of New Zealand between April 1998 and July 1999. The region includes urban, suburban, and rural areas and has a population of about one million. The source population for study participants comprised drivers of light vehicles on public roads. We included cars, vans, and light utility vehicles but excluded all vehicles licensed as heavy vehicles, taxis, and emergency vehicles. We excluded roads of the lowest functional classification as they make up a large proportion of road length but contribute only a small proportion of crashes in which a car occupant is injured or killed (injury crashes). ${ }^{12}$ We applied the definitions of geographical boundaries, time period, eligible vehicles, and eligible roads in an identical manner to cases and controls.

The study was approved by the Northern Regional Health Authority ethics committee. Informed consent was obtained from all participants for personal participation and use of records.

\section{Selection of cases}

We prospectively identified all drivers or passengers in eligible vehicles who were admitted to hospital or died as the result of a car crash in the study region through daily surveillance and case finding in the region's four

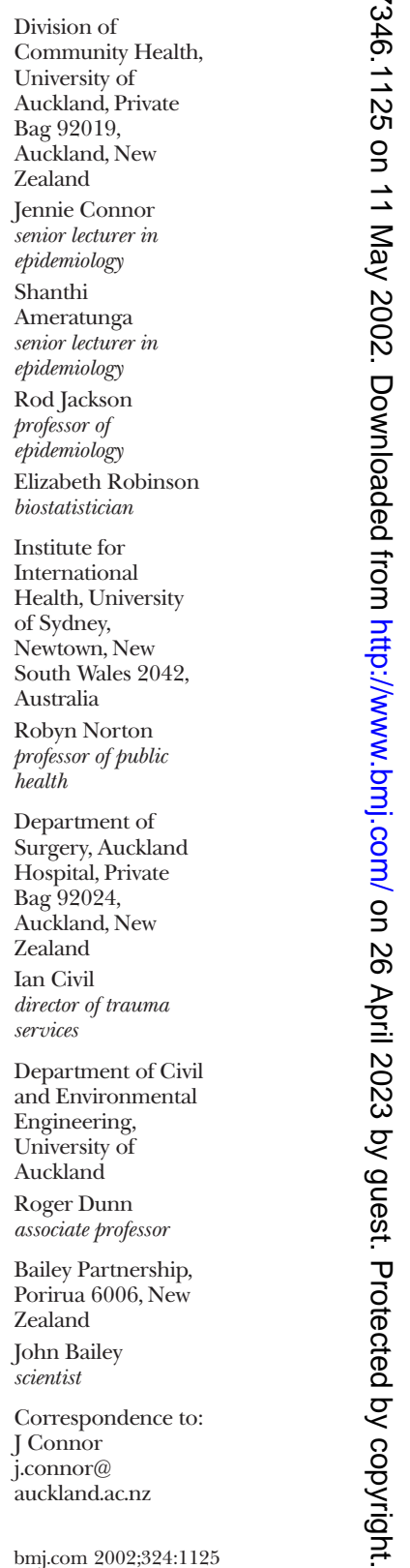


trauma hospitals and single coroner's office. Hospital trauma teams, emergency department staff, and the New Zealand police collaborated to ensure comprehensive case finding. In each case the driver of the vehicle was the key informant, whether or not the driver was injured, unless the driver was killed (see below).

\section{Selection of controls}

The control group comprised a sample of car drivers representative of all time spent by people driving on the region's roads during the study period. They were identified by cluster sampling of drivers at 69 randomly selected sites on the road network. The day of week, time of day, and direction of travel for each survey site were randomly assigned. Eligible vehicles passing each survey site during a two hour period were randomly sampled in proportion to the traffic volume at the site, which had been determined by earlier measurements. Cars were selected one at a time from traffic that had been slowed as it approached the site. On the busiest roads, we selected the first car identified after the previous one had been processed. At less busy sites, sampling was slowed by waiting for a predetermined period $(2,5$, or 15 minutes depending on traffic volume) between finishing with one car and selecting the next. We adjusted for residual differences in sampling fractions between survey sites by weighting the clusters of controls by the inverse of the sampling fraction from their site. Surveys were carried out at an average of one a week and recruitment approximately matched accrual of cases. When vehicles selected as controls did not stop or when it was not possible to stop traffic safely (for example, motorway sites), vehicle owners were identified through registration plates and telephone directories so that drivers could be invited to participate in the study.

\section{Data collection}

Interviews with case drivers were conducted face to face in hospital or by telephone at home. Proxy interviews were sought for drivers who sustained fatal injuries or were too ill to participate. For control drivers we obtained contact details, suitable interview times, and results of a breath test for alcohol at the roadside recruitment sites. Interviews were conducted by telephone. Many $(65 \%)$ of the interviews were carried out in the 48 hours after the crash or survey, although follow up calls were sometimes necessary. The highly structured interview was based on a questionnaire covering the circumstances of the current trip and many usual behaviours and background characteristics of the drivers. Questions related to the time of the crash in cases were indexed to the time of the roadside survey for control drivers, and the questions related to sleep comprised only a small part of the interview.

\section{Measures of driver sleepiness}

We used the Stanford sleepiness scale, a self rating scale, to quantify progressive steps in acute sleepiness. Respondents chose one of seven hierarchical statements that most closely described their level of alertness immediately before the crash or survey (see box). ${ }^{13}$ We used the Epworth sleepiness scale to measure chronic or usual daytime sleepiness. Respondents rated the likelihood (never, slight, moder- ate, high) that they would fall asleep in each of eight common situations, giving a total Epworth score in the range of 0-24: $<10$ is considered normal; 10-15 indicates moderate impairment, and 16-24 indicates severe impairment. ${ }^{14}$

We obtained the start and finish times of all sleep periods in the 24 hours before the crash or survey and the number of full nights of sleep (at least seven hours, mostly between $11 \mathrm{pm}$ and $7 \mathrm{am}$ ) in the previous week. We used five hours or less of sleep in the previous 24 hours as an indicator of acute sleep deprivation as it has been identified as a level at which performance starts to become impaired. ${ }^{11}$ We used no full nights of sleep in the previous seven nights as an indicator of chronic partial sleep deprivation. Participants were asked about symptoms of obstructive sleep apnoea (witnessed episodes of regular loud snoring, breathing pauses, and choking during sleep) and work patterns including types of shift. Because of the powerful effect of intrinsic circadian variability on alertness and performance ${ }^{15}$ we categorised time of day to reflect the known periods of decreased alertness (2-5 am, 2-5 pm, other times).

\section{Confounding variables}

Potential confounders that we considered in the analysis were age, sex, socioeconomic status, ethnicity, alcohol consumption, use of recreational drugs, time spent driving per week, vehicle speed, average traffic speed, type of road, and how long the person had been driving that day. We collected self reported data for all confounders except traffic speed and road type, which were ascertained from environmental surveys. We also obtained objective alcohol measurements with breathalyser tests for control drivers, and results of hospital blood tests, police blood tests, or police breathalyser results for drivers involved in crashes.

\section{Analysis}

To account for the sampling design we weighted control data by the inverse of the sampling fraction at the recruitment site and adjusted the variances of estimates to account for correlation within clusters of data from the same site. We used SUDAAN software for all analyses and calculated odds ratios using unconditional logistic regression. We assessed potential confounders using the change in estimate method, with a cut point of $5 \% .{ }^{16}$ The confounders we included in the analyses are shown in table 1 . We used self reported data on alcohol consumption for the statistical modelling rather than measured alcohol concentrations as they were more complete and the adjusted odds ratios did not vary significantly when one measure was substituted for the other (data not shown). We calculated population attributable risk estimates

\section{Stanford sleepiness scale}

1. Felt active, wide awake

2. Was functioning at a high level but not at peak

3. Felt relaxed, awake but not fully alert, responsive

4. Felt a little foggy headed

5. Felt foggy headed, had difficulty staying awake, was

beginning to lose track

6. Felt sleepy, would have preferred to lie down, woozy

7. Could not stay awake, sleep onset was imminent 
and their $95 \%$ confidence intervals according to the methods developed by Greenland. ${ }^{17} 18$

\section{Results}

We identified 615 eligible cases during the study period. These crashes resulted in 683 admissions to hospital with non-fatal injuries and 63 deaths. Two thirds of the deaths (43) and 60\% of admissions to hospital (405) involved drivers. Of the 615 case drivers or proxies eligible for the study, 571 (93\%) completed interviews, $30(5 \%)$ declined to participate, and $14(2 \%)$ could not be contacted. Fifty seven of the case interviews $(10 \%)$ were completed by a proxy respondent. Of the 746 control vehicles selected, 588 drivers completed interviews (79\%), 94 declined (12\%), 60 were untraceable $(8 \%)$, and four could not give informed consent because of language difficulties $(<1 \%)$.

Table 1 shows the distributions of measures of sleepiness and potential confounders. We used the prevalence of each characteristic in controls (adjusted for the sampling design) as an estimate of its prevalence in all driving undertaken in the study region.

There was a strong association between the level of acute driver sleepiness, as measured by the Stanford score, and the risk of injury crash (table 2). After we had controlled for the effects of age, sex, socioeconomic status, ethnicity, and alcohol, drivers with scores of 4 or above (those who identified any degree of sleepiness) had an 11-fold risk of injury crash compared with drivers in the most alert group (score 1). The comparison of these drivers (score $\geqslant 4$ ) with drivers who identified themselves as alert or relaxed (score $<4$ ), which is most relevant to usual driving, resulted in an eightfold increase in risk.

The two direct determinants of acute sleepiness that we measured, sleep deprivation and time of day, were also strongly associated with the risk of an injury crash. Drivers who reported five hours or less of sleep in the previous 24 hours were at significantly increased risk compared with those who had more than five hours. The most sleep deprived drivers (three hours or less) had a high risk of injury crash, but there were only two control drivers in this group (adjusted odds ratio $47,95 \%$ confidence interval 11 to 195 ). Drivers with five to seven hours of sleep were not at any greater risk than those with more than seven hours. The risk associated with driving between 2 am and 5 am was more than five times that of other times of day, but we found no increase in risk associated with the secondary circadian dip in mid-afternoon (data not shown).

We observed no increase in risk with measures of chronic sleepiness (table 2). An Epworth score of 10-15 was associated with a reduction in risk compared with drivers with a normal score $(<10)$, and regular loud snorers were also at less risk than non-snorers. High Epworth scores (16-24), no full nights of sleep in the previous week, three symptoms of sleep apnoea, and night work were not associated with a significant increase or decrease in risk.

We found no major alteration in the effect estimates when we excluded proxy respondents or restricted analyses to drivers who had not been drinking (table 2).
Table 1 Distribution of measures of sleepiness and confounding variables for drivers in crashes that resulted in injury to car occupant (cases) and representative sample of drivers not involved in crashes (controls)*

\begin{tabular}{|c|c|c|}
\hline & Cases $(n=571)$ & Controls $(n=588)$ \\
\hline \multicolumn{3}{|l|}{ Stanford sleepiness scale: } \\
\hline 1 (most alert) & $175(34.3)$ & $322(54.4)$ \\
\hline $2-3$ & $272(53.3)$ & $256(44.6)$ \\
\hline $4-7$ & $63(12.4)$ & $8(1.0)$ \\
\hline \multicolumn{3}{|l|}{ Sleep in previous 24 hours: } \\
\hline$>5$ hours & $464(87.7)$ & $554(96.9)$ \\
\hline$\leqslant 5$ hours & $65(12.3)$ & $30(3.1)$ \\
\hline \multicolumn{3}{|l|}{ Time of day: } \\
\hline $2 \mathrm{am}-5 \mathrm{am}$ & $46(8.1)$ & $17(0.4)$ \\
\hline $2 \mathrm{pm}-5 \mathrm{pm}$ & $107(18.7)$ & $136(27.1)$ \\
\hline Other & $418(73.2)$ & $435(72.5)$ \\
\hline \multicolumn{3}{|l|}{ Epworth sleepiness scale: } \\
\hline$<10$ (normal) & $516(96.1)$ & $531(90.8)$ \\
\hline $10-15$ & $17(3.2)$ & $48(7.9)$ \\
\hline $16-24$ & $4(0.7)$ & $6(1.3)$ \\
\hline \multicolumn{3}{|l|}{ Sleep in previous week: } \\
\hline At least 1 full night† & $474(88.6)$ & $544(92.3)$ \\
\hline No full night's sleep & $61(11.4)$ & $44(7.7)$ \\
\hline \multicolumn{3}{|l|}{ Regular loud snoring: } \\
\hline No & $375(70.2)$ & $379(62.8)$ \\
\hline Yes & $159(29.8)$ & $204(37.2)$ \\
\hline \multicolumn{3}{|l|}{ Triad of sleep apnoea symptomsł: } \\
\hline No & $528(98.1)$ & $581(98.4)$ \\
\hline Yes & $10(1.9)$ & $6(1.6)$ \\
\hline \multicolumn{3}{|l|}{ Night work§: } \\
\hline No & $511(90.6)$ & $520(91.9)$ \\
\hline Yes & $53(9.4)$ & $61(8.1)$ \\
\hline \multicolumn{3}{|l|}{ Sex: } \\
\hline Women & $198(34.7)$ & $226(41.3)$ \\
\hline Men & $373(65.3)$ & $362(58.7)$ \\
\hline \multicolumn{3}{|l|}{ Age group (years): } \\
\hline $15-24$ & $195(34.2)$ & $91(13.7)$ \\
\hline $25-34$ & $133(23.3)$ & $125(22.3)$ \\
\hline $35-44$ & $85(14.9)$ & $154(24.5)$ \\
\hline $45-54$ & $61(10.7)$ & $107(19.6)$ \\
\hline $55-64$ & $39(6.8)$ & $80(14.2)$ \\
\hline $65-80$ & $58(10.2)$ & $31(5.6)$ \\
\hline \multicolumn{3}{|c|}{ Self reported alcohol consumption in previous 6 hours (standard drinks): } \\
\hline 0 & $418(76.4)$ & $537(94.7)$ \\
\hline 1 & $15(2.7)$ & $15(1.8)$ \\
\hline 2 & $20(3.7)$ & $21(2.7)$ \\
\hline$\geqslant 3$ & $94(17.18)$ & $5(0.8)$ \\
\hline \multicolumn{3}{|l|}{ Measured alcohol level $(\mathrm{mg} / 100 \mathrm{ml})$ : } \\
\hline 0 & $263(63.7)$ & $474(98.0)$ \\
\hline $1-50$ & $32(7.8)$ & $9(1.5)$ \\
\hline$>50$ & $118(28.6)$ & $3(0.5)$ \\
\hline \multicolumn{3}{|l|}{ Educational level: } \\
\hline$\leqslant 3$ year high school (left at age $\leqslant 15$ years) & $251(44.4)$ & $157(25.6)$ \\
\hline$>3$ years high school & $137(24.2)$ & $154(25.1)$ \\
\hline Further education & $178(31.5)$ & $276(49.3)$ \\
\hline \multicolumn{3}{|l|}{ Ethnicity: } \\
\hline White/European & $313(54.8)$ & $444(74.7)$ \\
\hline Maori & $117(20.5)$ & $61(9.2)$ \\
\hline Pacific Islands & $86(15.1)$ & $36(6.1)$ \\
\hline Other & $55(9.6)$ & $47(10.0)$ \\
\hline
\end{tabular}

*Proportions of controls are adjusted for sampling design. Column totals may differ due to missing data. †At least seven hours, mostly between $11 \mathrm{pm}$ and $7 \mathrm{am}$.

$\ddagger$ Witnessed episodes of choking and breathing pauses during sleep and regular loud snoring

§Included rotating shifts with nights, permanent night shift, and other work patterns that required regularly starting before 6 am or finishing after midnight.

The population attributable risk is the proportion by which the incidence of injury crashes would be reduced if a specific risk factor was eliminated from the population. If we assume that the associations are causal and unconfounded, the population attributable 
Table 2 Association of variables related to sleep with risk of crash in which car occupant was injured. Figures are adjusted odds ratios and 95\% confidence intervals for multivariable models*

\begin{tabular}{lccc} 
& $\begin{array}{c}\text { Whole study } \\
\text { population }\end{array}$ & $\begin{array}{c}\text { Proxy respondents } \\
\text { excluded }\end{array}$ & $\begin{array}{c}\text { Drinking drivers } \\
\text { excluded }\end{array}$ \\
\hline Acute sleepiness & & & \\
\hline Stanford sleepiness scale: & 1 & 1 & 1 \\
\hline 1 (most alert) & $1.7(1.1$ to 2.5$)$ & $1.6(1.1$ to 2.4$)$ & $1.6(1.1$ to 2.4$)$ \\
\hline $2-3$ & $11.0(4.5$ to 27.2$)$ & $10.2(4.2$ to 24.9$)$ & $9.4(3.7$ to 24.0$)$ \\
\hline $4-7$ & &
\end{tabular}

Stanford sleepiness scale:

\begin{tabular}{lccc}
\hline $1-3$ & 1 & 1 & 1 \\
\hline $4-7$ & $8.2(3.4$ to 19.7$)$ & $8.1(3.4$ to 19.7$)$ & $7.3(2.9$ to 18.3$)$ \\
\hline Sleep in previous 24 hours: & & & \\
\hline$>5$ hours & 1 & 1 & 1 \\
\hline$\leqslant 5$ hours & $2.7(1.4$ to 5.4$)$ & $2.9(1.5$ to 5.8$)$ & $2.9(1.5$ to 5.6$)$ \\
\hline Time of day: & & & \\
\hline $2-5$ am & $5.6(1.4$ to 22.7$)$ & $5.7(1.4$ to 23.0$)$ & $6.6(1.6$ to 27.4$)$ \\
\hline Other & 1 & 1 & 1 \\
\hline
\end{tabular}

Chronic sleepiness

Epworth sleepiness scale:

\begin{tabular}{lccc}
\hline$<10$ (normal) & 1 & 1 & 1 \\
\hline $10-15$ & $0.4(0.2$ to 0.8$)$ & $0.4(0.2$ to 0.7$)$ & $0.4(0.2$ to 0.8$)$ \\
\hline $16-24$ & $0.7(0.2$ to 2.5$)$ & $0.7(0.2$ to 2.5$)$ & $1.1(0.3$ to 4.7$)$ \\
\hline Sleep in previous week: & & & \\
\hline At least 1 full night† & 1 & 1 & 1 \\
\hline No full night's sleep & $1.5(0.9$ to 2.4$)$ & $1.5(0.9$ to 2.5$)$ & $1.6(0.9$ to 2.7$)$ \\
\hline
\end{tabular}

Regular loud snoring:

\begin{tabular}{lccc}
\hline No & 1 & 1 & 1 \\
\hline Yes & $0.6(0.4$ to 0.9$)$ & $0.6(0.4$ to 0.9$)$ & $0.6(0.4$ to 0.8$)$ \\
\hline
\end{tabular}

Triad of sleep apnoea symptomsł:

\begin{tabular}{lccc}
\hline No & 1 & 1 & 1 \\
\hline Yes & $1.4(0.5$ to 4.0$)$ & $1.5(0.6$ to 4.3$)$ & $1.3(0.4$ to 3.7$)$ \\
\hline
\end{tabular}

Night work§:

\begin{tabular}{lccc}
\hline No & 1 & 1 & 1 \\
\hline Yes & $0.9(0.5$ to 1.5$)$ & $0.9(0.5$ to 1.5$)$ & $1.0(0.5$ to 1.7$)$ \\
\hline
\end{tabular}

*Logistic regression analysis included age group, sex, educational level, ethnicity, and self reported alcohol consumption in all models. Time of day included in all models except Stanford score, for which it is a determinant.

†At least seven hours, mostly between $11 \mathrm{pm}$ and $7 \mathrm{am}$.

$\ddagger$ Witnessed episodes of choking and breathing pauses while sleeping and regular loud snoring

§Included rotating shifts with nights, permanent night shift, and other work patterns that required regularly starting before 6 am or finishing after midnight.

risks were $11 \%$ (8\% to 15\%) for feeling sleepy (Stanford score $4-7 v 1-3$ ), $8 \%$ (5\% to $13 \%$ ) for sleeping less than five hours in the previous 24 hours, and $7 \%$ (4\% to $11 \%$ ) for driving between 2 am and $5 \mathrm{am}$. The population attributable risk for having at least one of these three risk factors was $19 \%$ (15\% to $25 \%$ ).

\section{Discussion}

We found a strong association between acute sleepiness in car drivers and the risk of a crash in which a car occupant was injured or killed that was independent of the effects of acute alcohol consumption and other major confounding factors. Decreased levels of self reported alertness were associated with increased risk. There was an eightfold increased risk if drivers reported sleepiness and almost a threefold risk for drivers who were driving after five hours or less of sleep. We also confirmed the increased risk of an injury crash associated with driving in the early hours of the morning, observed in many routine surveillance systems. In contrast, we found no significant increase in risk observed with measures of chronic sleepiness.

\section{Possible bias}

It is unlikely that our results can be explained by selection bias as we identified all cases and a representative sample of controls from the study region over the study period and obtained high response rates. We also minimised information bias by using standard interviews and a reference point for acute exposures (crash or survey). Biases may remain however, particularly recall bias, even though sleepiness was not an identified focus of the study. The risk associated with a Stanford score of $\geqslant 4$ is the measure most likely to be affected by recall bias and could, therefore, be somewhat inflated. The measurement of acute sleep deprivation, based on start and finish times of sleep periods, is less likely to be biased. We verified time of day, which has been used as a proxy measure of crashes related to sleepiness in previous research, ${ }^{19}$ though the precision of estimates involving time of day was reduced by the clustering in time of control recruitment. Chronic sleepiness is difficult to measure by self report, ${ }^{1}$ and the lack of effect associated with measures of chronic sleepiness in this study may be due in part to the methods used. Some studies have found the Epworth sleepiness scale to be an insensitive measure, ${ }^{20}$ whereas others have found it to be associated with risk of crash (although not injury). ${ }^{21}$ The use of symptoms alone as an indicator of obstructive sleep apnoea may have resulted in misclassification $^{22}$ that could have affected the validity and precision of the associated risk estimate.

Only two previous case control studies of car crashes have examined factors related to sleep ${ }^{20}{ }^{23}$ and only one of them measured acute sleepiness and sleep deprivation as exposures. ${ }^{23}$ Although the outcome measure was crash rather than injury and the setting rural rather than predominantly urban, this recent study from Washington state found a significant increase in risk associated with nine or less hours sleep in the previous 48 hours and with self reported sleepiness, broadly consistent with our results.

\section{Implementation of findings}

Our study shows that acute sleepiness makes a considerable contribution to the burden of car crash injuries in this population. Moreover, reductions in the prevalence of specific behaviours may result in reduction in injuries or death of up to $19 \%$. It provides some simple evidence based messages to disseminate with regard to specific driver behaviours in place of general advice against driving while sleepy. The priority given to developing and implementing interventions to prevent crashes related to sleepiness needs to reflect the contribution of driver sleepiness to the overall burden of injury from car crashes, and any such interventions should target the specific behaviours where there is evidence of potential benefit.

We thank the study participants; Brenda Wigmore, Cherie Lovell, Desiree Lloydd, Paul Burnham, and other data collection staff at the Injury Prevention Research Centre; trauma teams and emergency department staff at contributing hospitals; the coroner's office; and the Land Transport Safety Authority, New Zealand police, and Transit New Zealand.

Contributors: JC contributed to the study design, coordinated data collection, and was mainly responsible for the statistical analysis and writing the paper and is guarantor. $\mathrm{RN}$ and $\mathrm{RJ}$ were mainly responsible for the study design and contributed to the interpretation of the data and writing the paper. SA, ER, IC, 


\section{What is already known on this topic}

Driver sleepiness is considered a potentially important risk factor for car crashes and related injuries but the association has not been reliably quantified

Published estimates of the proportion of car crashes attributable to driver sleepiness vary from about $3 \%$ to $30 \%$

\section{What this study adds}

Driving while feeling sleepy, driving after five hours or less of sleep, and driving between 2 am and 5 am were associated with a substantial increase in the risk of a car crash resulting in serious injury or death

Reduction in the prevalence of these three behaviours may reduce the incidence of injury crashes by up to $19 \%$

$\mathrm{RD}$, and JB contributed to the study design and writing of the paper. ER also contributed to the statistical analysis.

Funding: Health Research Council of New Zealand and Transit New Zealand. JC is supported by the Health Research Council and the Australasian Faculty of Public Health Medicine. Competing interests: None declared.

1 Lyznicki JM, Doege TC, Davis RM, Williams MA. Sleepiness, driving, and motor vehicle crashes. JAMA 1998;279:1908-13.

2 Philip P, Vervialle F, Le Breton P, Taillard J, Horne JA. Fatigue, alcohol, and serious road crashes in France: factorial study of national data. $B M J$ 2001;322:829-30.

3 Pierce RJ. Driver sleepiness: occupational screening and the physician's role. Aust N Z J Med 1999;29:658-61.

4 Philip P, Taillard J, Guilleminault C, Quera Salva MA, Bioulac B, Ohayon M. Long distance driving and self-induced sleep deprivation among automobile drivers. Sleep 1999;22:475-80.
5 Connor J, Whitlock G, Norton R, Jackson R. The role of driver sleepiness in car crashes: a systematic review of epidemiological studies. Accid Anal Prev 2001;33:31-41.

6 Connor J, Norton R, Ameratunga S, Robinson E, Wigmore B, Jackson R. Prevalence of driver sleepiness in a random population-based sample of car driving. Sleep 2001;24:688-94.

7 Akerstedt T. Work hours, sleepiness and the underlying mechanisms J Sleep Res 1995;4(suppl 1):15-22.

8 Dinges D, Kribbs N. Performing while sleepy: effects of experimentallyinduced sleepiness. In: Monk T, ed. Sleep, sleepiness and performance. New York:John Wiley, 1991:98-128.

9 Expert Panel on Driver Fatigue and Sleepiness. Drowsy driving and automobile crashes. Washington, DC: National Center for Sleep Disorders Research/National Highway Traffic Safety Authority, 1997.

10 Pilcher JJ, Huffcutt AI. Effects of sleep deprivation on performance: a meta-analysis. Sleep 1996;19:318-26.

11 Bonnet M. Sleep deprivation. In: Kryger M, Roth T, Dement W, ed. Principles and practice of sleep medicine. 3rd ed. Philadelphia, PA: WB Saunders, 2000.

12 Land Transport Safety Authority. Accident investigation system (AIS) 1993 1997. Wellington: LTSA, 1998.

13 Hoddes E, Zarcone V, Smythe H, Phillips R, Dement W. Quantification of sleepiness: a new approach. Psychophysiology 1973;10:431-6.

14 Johns M. A new method for measuring daytime sleepiness: the Epworth sleepiness scale. Sleep 1991;14:54-5.

15 Roehrs T, Carskadon M, Dement W. Daytime sleepiness and alertness. In: Kryger M, Roth T, Dement W, ed. Principles and practice of sleep medicine. 3rd ed. Philadelphia, PA: WB Saunders, 2000.

16 Greenland S. Modeling and variable selection in epidemiologic analysis. Am J Public Health 1989;79:340-9.

17 Benichou J. Methods of adjustment for estimating the attributable risk in case-control studies: a review. Stat Med 1991;10:1753-73.

18 Coughlin SS, Benichou J, Weed DL. Attributable risk estimation in casecontrol studies. Epidemiol Rev 1994;16:51-64.

19 Leger D. The cost of sleep-related accidents: a report for the National Commission on Sleep Disorders Research. Sleep 1994;17:84-93.

20 Terán-Santos J, Jiménez-Gómez A, Cordero-Guevara J. The association between sleep apnea and the risk of traffic accidents. $N$ Engl J Med 1999:340:847-51.

21 Maycock G. Driver sleepiness as a factor in car and HGV accidents. Crowthorne, Berkshire: Transport Research Laboratory, 1995:39.

22 Chervin R. Use of clinical tools and tests in sleep medicine. In: Kryger M, Roth T, Dement W, ed. Principles and practice of sleep medicine. 3rd ed. Philadelphia, PA: WB Saunders, 2000.

23 Cummings P, Koepsell TD, Moffat JM, Rivara FD. Drowsiness, counter-measures to drowsiness, and the risk of a motor vehicle crash. Inj Prev 2001;7:194-9

(Accepted 29 January 2002) 